\title{
A violência escolar em um colégio de Foz do Iguaçu-PR
}

Irani Batista Araújo ${ }^{1}$

\section{Resumo}

O presente texto busca construir uma visão da violência escolar entre adolescentes no colégio do Porto Belo na cidade de Foz do Iguaçu. Este artigo apresenta as manifestações praticadas pelos atores que compõem a instituição de ensino, práticas que estão relacionadas tanto aos problemas internos como externos do cotidiano escolar. As informações contidas no artigo têm como base dados obtidos durante a pesquisa de campo realizada na instituição de ensino no ano de 2014.

Palavras-chave: adolescente; escola; violência.

\begin{abstract}
This paper seeks to build a vision of school violence among adolescents in the school Porto Belo in Foz do Iguaçu. This article presents the manifestations practiced by actors in the educational institution, practices that are related to both internal and external problems of everyday school life. The information in the article are based on data obtained during the field research in educational institution in 2014.
\end{abstract}

Key-words: adolescent; school; violence.

\section{O fenômeno violência na região de fronteira.}

O fenômeno da violência existe em Foz do Iguaçu desde antes da construção da Itaipu ${ }^{3}$, embora alguns autores como Catta (2003) e Lima (2012) pontuem que o município se tornou um caos

\footnotetext{
${ }^{1}$ Possui graduação em Pedagogia com Licenciatura Plena pela Universidade Federal do Rio Grande do Norte. Atua como professora na rede Municipal de Foz do Iguaçu e como Pedagoga na rede pública Estadual do Paraná. Pós Graduação em Pré Escolar e Alfabetização e em Métodos e Técnicas de Ensino.
} 
somente após o término do megaprojeto. Esses autores produziram uma imagem romântica de uma cidade, onde a população podia usufruir de suas riquezas (lazer e turismo). Contudo, observa-se que as desapropriações realizadas pela hidrelétrica em construção já configuravam uma violência para com as populações que foram "expulsas" de suas moradias (RIBEIRO, 2002). Os fatos sugerem que a violência apenas se intensificou após o final da obra, que, segundo Catta (2003) foi determinante para o crescimento da criminalidade na cidade, já que os operários dispensados se somaram a outro contingente de desempregados que viviam de ocupações temporárias e informais.

A fronteira entre Brasil (Foz do Iguaçu) e Paraguai (Ciudad Del Leste) é conhecida por vários fatores que a caracterizam com preconceitos devido às inúmeras práticas ilegais desenvolvidas na região. Por sua ponte internacional atravessa milhares de pessoas em busca de melhores preços, mesmo sabendo que existe o risco de ser falsificado, visto que, no imaginário popular, o Paraguai é conhecido como o "paraíso da falsificação". Por outro lado, não são somente as compras de importados que se presencia na fronteira, mas um aglomerado de cores, vestes, idiomas, moedas corrente (peso, dólar, real e guarani). Enfim, visualiza-se a convivência de múltiplos aspectos que a caracterizam como um espaço singular.

Em relação à fronteira do Brasil com a Argentina (Puerto Iguazú), observa-se uma realidade um pouco diferente da anterior, pois o fluxo de compristas é menor e a fiscalização aduaneira das autoridades de saúde e de imigração é mais rigorosa (KLEINSCHMITT, AZEVEDO e CARDIN, 2013). Segundo os autores, os índices de delinquência são baixos, fator que sugere a dedução de que a violência é um elemento que não interfere no movimento dos turistas que vão à busca de gêneros alimentícios, bebidas e das famosas roupas de couro. Como nas duas cidades, Foz do Iguaçu também vive do turismo (seja de compras, passeio ou eventos) que colabora para alavancar a economia local, empregando um contingente de pessoas em ocupações diversas.

\footnotetext{
${ }^{3}$ A Hidrelétrica de Itaipu é o resultado de um acordo em conjunto dos governos do Brasil e do Paraguai, objetivando aproveitar o potencial hidráulico das águas do rio Paraná. As obras iniciaram em1975 e em novembro de 1992, a barragem estava erguida (Fonte: https://www.pmfi.pr.gov.br).
} 
Nas suas peculiaridades, a cidade de Foz do Iguaçu possui, segundo o último Censo do IBGE ${ }^{4}$ (2010), 256.088 habitantes. Tendo como principal fonte econômica o turismo, seguido da geração de energia elétrica, visualiza-se no município uma infraestrutura de hotéis e restaurantes e estruturas para realização de eventos (congressos, competições, feiras, etc.). Outro marco de avanço para a cidade, segundo observações de Lima (2010, p. 205), é a fundação da Universidade Federal da Integração Latino Americana $\left(\mathrm{UNILA}^{5}\right.$ ) que é tida como uma grande esperança para o desenvolvimento da cidade que, no futuro, poderá tornar-se um grande polo universitário, pois, é frequentada por milhares de alunos oriundos de todas as regiões do Brasil e da América Latina.

Em meio a muitas mudanças e a velocidade cotidiana da fronteira, fatos revelam que a violência, principalmente entre a população jovem, é um fator preocupante para os órgãos de segurança pública da cidade. Neste sentido, Luz (2008, p. 02) observa que "oito a cada dez adolescentes atendidos em abrigos de Foz do Iguaçu recebem ameaça de morte por parte de traficantes". Geralmente, estão fora da escola com a família nas ruas "brincando" de vender doces, salgados e CDs, principalmente na região da Ponte da Amizade ou transportando mercadorias do Paraguai, até ficarem nas mãos do crime organizado. Segundo o mesmo autor, 504 jovens de 12 a 18 anos foram assassinados em Foz do Iguaçu entre 2001 e 2007. Tais apontamentos reforçam a ideia de que Foz do Iguaçu é a campeã em homicídios juvenis no país, com média de 234 mortes a cada cem mil habitantes.

A violência tem sido um fenômeno preocupante no Brasil e em Foz do Iguaçu em particular. Alguns fatores são apontados como facilitadores como o contrabando de armas, o tráfico de drogas e a localização geográfica da cidade, entre outros. Ainda que:

\footnotetext{
${ }^{4} \mathrm{O}$ Instituto Brasileiro de Geografia e Estatística (IBGE) - realiza censos nas três esferas governamentais: federal, estadual e municipal e/ou para outras instituições e o público em geral. Consultar: https:// www.ibge.gov.br.

3 Universidade Federal da Integração Latino-Americana (Unila). Surgiu como proposta diferenciada. Sua missão institucional está focada na formação de recursos humanos para contribuir com a integração latino-americana, o desenvolvimento regional e o intercâmbio cultural, científico e educacional da América Latina, especialmente, no Mercado Comum do Sul.

${ }_{4}$ Segundo Vicente de Paula Faleiros $(2008$, p. 72) "as despesas para o setor da educação não são somente da mais-valia retirada do capital, mas pelo seu crescimento elas aumentam, também, o valor da força de trabalho, e, assim, diminuem a taxa de mais-valia, que de outra forma seria estável".
} 
O perfil dos adolescentes assassinados em Foz do Iguaçu não difere muito de outros adolescentes mortos em outras cidades do país, apenas a cor predominante, pelos traços da colonização da região, a maioria dos adolescentes mortos era da cor branca (67\%), porém, a grande maioria era do sexo masculino $(93 \%)$, pobre $(38 \%)$ ou muito pobre $(48 \%)$, trabalhadores não qualificados (44\%), não concluíram o ensino fundamental (90\%), tiveram envolvimento com drogas $(21 \%)$ e foram mortos por armas de fogo (89\%). (LUZ, 2008, p. 11).

Num sentido mais amplo, a pesquisa realizada por Gonçalves, Cassuce e Galante (2010) sobre o número de homicídios para cada 100 mil habitantes nas 10 cidades mais populosas do Estado do Paraná em 1980 e 2002, Foz do Iguaçu obteve a quinta colocação, com o indicador de 35, 94 homicídios (1980). Em 2002, quase triplicou para 97, 09. O resultado do período da pesquisa é um acréscimo de 170, ou seja, 14 \% no número de homicídios na cidade. Os autores optaram por defender a teoria de que o aumento da criminalidade tem influência de fatores conjunturais e estruturais que incluem fatores socioeconômicos e de localização da cidade.

Ainda, segundo os mesmos autores, "no ano de 2000, as regiões fronteiriças apresentaram 10,56 homicídios para cada 100 mil habitantes a mais que outros municípios do Estado" (GONÇALVES, CASSUCE E GALANTE, 2010, p. 40). O aumento dessa relação evidencia o crescimento da violência nessas regiões, sugerindo a organização sistematizada com que as quadrilhas atuam nesses locais e a fiscalização insuficiente devido ao número reduzido de policiais e fiscais que trabalham nas regiões fronteiriças, o que, a título de hipótese, pode-se deduzir que facilita o acesso às drogas e que o custo local do consumo é facilitado às populações usuárias dessas localidades.

A localização dos municípios em relação às regiões fronteiriças foi outro fator que afetou, consideravelmente, os índices de criminalidade. Os resultados encontrados comprovam que os municípios que fazem fronteira com o Paraguai têm seus índices de violência, na média, superiores aos demais. Isso comprova o fato dessa ser uma área crítica quando se trata de controle da violência, o que já não ocorre em municípios que fazem fronteira com a Argentina. Uma provável explicação seria a de que o comércio com a Argentina apresenta características diferentes daquelas do comércio realizado com o Paraguai. (GONÇALVES; CASSUCE; GALANTE, 2010, p. 41). 
Esses dados seriam suficientes para gerar mais divergências com os órgãos de Segurança Pública do Paraná que contestam os números divulgados justificando, de certa maneira, o crescimento da criminalidade. Segundo os mesmos, comparar Foz do Iguaçu com outra cidade brasileira é uma atitude equivocada, pois a cidade está na rota utilizada por traficantes e contrabandistas. Segundo publicação de Wojciechowsk (2009, p.02) "o acelerado crescimento demográfico e a falta de oportunidades econômicas legais, induzem as pessoas a se envolverem com o ilegal". Na pesquisa realizada por Cardin (2013), observa-se que a violência entre o público jovem no município teve uma ascensão nos anos de 2005 a 2007, seguido de uma significativa queda em 2008, explicada pelo autor como sendo derivada de "choque de gestão" (CARDIN, 2013, p. 177).

Estudos realizados sobre o assunto constatam que a violência como forma de expressão tem sido marca juvenil, independentemente dos modos de inserção social dos mesmos. Os adolescentes, geralmente, justificam suas atitudes como uma atração pelas ações criminosas que transcendem a aquisição de bens materiais e o incentivo que o mundo do consumismo proporciona. Todavia, conforme os dados fornecidos por Luz (2008), a maioria dos jovens assassinados era de cor branca (67\%), e o índice de pobres não atingiu 50\%, informações que sustentam as ideias de Marília Pontes Sposito. Segundo a autora, é preciso romper com o pressuposto de que o jovem pobre e negro é indicativo de problema social:

Esses jovens, como a maior parte da juventude urbana e pobre, não constituem um risco social e um grave problema para a sociedade. A vivência da pobreza não significa imediatamente predisposição para a violência. Há expressivos segmentos de jovens das camadas populares que buscam estratégias de sobrevivência para eles e suas famílias; trabalham temporariamente e em condições difíceis, lutam para superar a diversidade e as desigualdades sociais. (SPOSITO, 2007, p. 132).

\footnotetext{
${ }^{6} \mathrm{O}$ choque de gestão explicitado pelo autor diz respeito à convergência de um conjunto diferenciado de políticas públicas direcionadas à normatização das práticas de trabalho na região. Na primeira década do Século XXI, mais especificamente durante as primeiras gestões do PT no Governo Federal, foram desenvolvidas medidas de universalização do ensino e ampliação dos cursos profissionalizantes para a melhoria da qualificação da força de trabalho, uma coibição mais intensiva do circuito sacoleiro na região da Ponte da Amizade, a tentativa de inserção do sacoleiro por meio da Lei do Micro Empreendedor, o desenvolvimento de práticas midiáticas para estigmatizar o contrabando, o combate violento as práticas sociais desenvolvidas de maneira paralela ao mercado regulamentado e, por fim, um conjunto de operações policiais nas regiões periféricas da cidade. Todos estes esforços associados sintetizam o interesse em disciplinar os usos e costumes na fronteira.
} 
Todos esses elementos são valiosos para a análise do cenário fronteiriço, pois, devido à sua complexidade, a violência tem sido um desafio às autoridades públicas que precisam se utilizar de estratégias eficientes, concretas e eficazes para, pelo menos, amenizar o problema. Segundo Andrade (2012), há uma associação entre a taxa de homicídios e a desigualdade socioeconômica, como também, entre as ocupações informais que, no começou do Século XXI, chegaram a alcançar o índice de 62,08\% da população iguaçuense em meados da década de 1990, tornando-se um grave problema social (ANDRADE, 2012, p. 385). Para esse autor, são nas atividades informais que o público jovenil encontra-se numa situação de risco e de vulnerabilidade à violência fatal, pois, muitas vezes, é por meio dessas práticas que os jovens pobres têm encontrado um espaço na sociedade, até porque, para trazer mercadorias do país vizinho, não é preciso ter qualificação profissional e nem escolaridade avançada, elementos que facilitam a migração do adolescente para o ilícito.

\section{O cenário da violência e seus atores.}

A cidade de Foz do Iguaçu está dividida em doze regiões. A região dois é denominada de 'Região da Vila C'. Limitada ao norte pela Hidrelétrica de Itaipu (Lago), a oeste pelo Rio Paraná, a leste pela Subestação de Furnas e ao sul pelo Rio Mathias Almada. O Porto Belo está inserido na região dois, bem como, é um dos mais antigos bairros do município. Contudo, as reivindicações dos moradores para o bairro são muitas: asfalto; praças com melhor estrutura (iluminação, árvores, bancos); mais apoio à terceira idade; academia comunitária ao ar livre; cursos do Provopar (manicure, cabeleireiro, chefe de cozinha, artesanato, entre outros) mais próximo do bairro; policiamento frequente; projetos direcionados aos adolescentes (para não ficarem ociosos nas ruas); melhorias no posto de saúde, entre outras.

A região possui cerca de trinta e três comunidades (bairros, loteamentos, vilas), com 38.229 habitantes em agosto de 2014. Possui uma infraestrutura que atende às necessidades da população, porém, de maneira restrita. A maioria da sua população é composta por muitos ex-trabalhadores da Usina de Itaipu e por trabalhadores do comércio informal do Paraguai (laranjas/muambeiros). Dispõe 
de atrativos turísticos, como: o Centro de Recepções de Visitantes da Itaipu, o Ecomuseu de Itaipu, o Refúgio Biológico e o Templo Budista. Além disso, a região contemplada com quatro unidades de educação superior: Unioeste ${ }^{7}$, Uniamérica ${ }^{8}$, Unila ${ }^{9}$ e a UAB, ${ }^{10}$. As duas últimas funcionam nas instalações do Parque Tecnológico da Itaipu (PTI).

A denominação do bairro Porto Belo está relacionada à existência de um porto durante a década de 1960 que era utilizado para exportação da madeira Araucária para o Paraguai, pelo rio Paraná. Quando a estrutura foi desativada, o seu nome foi mantido ${ }^{11}$. O bairro é ocupado por moradores pertencentes à classe média e baixa e inclui, cerca de treze pequenos bairros circunvizinhos (alguns bairros só têm 5 ou 6 ruas), com modestos comércios - panificadora, salão de beleza, mercadinhos, bares, farmácia e lanchonetes, entre outros. Algumas ruas de calçamento poliédrico e outras asfaltadas as que passam transporte coletivo. Possuí três escolas municipais, um colégio estadual, uma unidade de saúde pública, três creches e para o lazer da população local, as opções se restringem a uma quadra de esportes, um campo de futebol e pracinhas mal conservadas - mato, bancos quebrados, não há parquinhos para as crianças e nem academia ao ar livre para a terceira idade.

O interesse pela pesquisa surgiu a partir de observações e situações vivenciadas no Colégio Estadual Professora Carmelita de Souza Dias do bairro durante o período em trabalhei na localidade na função de pedagoga. Com a intenção de sanar minha curiosidade, elaborei um projeto de pesquisa o qual foi desenvolvida uma dissertação de mestrado. Foram entrevistados 56 adolescentes em duas turmas $-9^{\circ}$ ano $\mathrm{A}$ e $1^{\mathrm{a}}$ séria $\mathrm{A}$ - do turno da manhã. As informações foram obtidas por meio de um

\footnotetext{
${ }^{7}$ Universidade Estadual do Oeste do Paraná (Unioeste) - constitui-se numa Instituição de Ensino Superior com mais 3 campi - Toledo, Cascavel e Marechal Cândido Rondon - no Oeste e um em Francisco Beltrão no Sudoeste do estado e três extensões: Santa Helena, Palotina e Medianeira. DEBALD; CARDIN; SOUZA (orgs.), (2009, p. 27).

8 Faculdade União das Américas (Uniamérica), inaugurada em 12/07/2001 e início das atividades acadêmicas em13/08/2011, tem a missão de transformar Foz do Iguaçu em um Centro de Ensino Superior de Excelência; formar profissionais de alta qualificação e aprimorar o desenvolvimento sustentável local e regional. Disponível em: https:// www.uniamerica.br. Acesso em: 15 set. 2014.

${ }^{9}$ Universidade Federal da Integração Latino-Americana (Unila). Surgiu como proposta diferenciada. Sua missão institucional está focada na formação de recursos humanos para contribuir com a integração latino-americana, o desenvolvimento regional e o intercâmbio cultural, científico e educacional da América Latina, especialmente, no Mercado Comum do Sul.

${ }^{10}$ Universidade Aberta do Brasil (UAB) - Polo Universitário de Apoio Presencial Darcy Ribeiro, criada por meio de parceria entre a Prefeitura de Foz do Iguaçu, o PTI e o Ministério da Educação. O objetivo da UAB é ampliar o número de vagas da educação superior, especialmente para a população que não tem acesso à formação universitária.

${ }^{11}$ Informações obtidas como o Sr. Ricardo Lemmertz, um dos primeiros moradores da região do Porto Belo.
} 
questionário, de observações internas no ambiente escolar e de entrevistas abertas com os interlocutores. Os adolescentes declarantes estão entre 13 e 17 anos $^{12}$. A maioria mora com os pais, só estuda, é de cor branca ${ }^{13}$, seguida da cor parda, são mantidos pelos pais e irmãos maiores e todos são solteiros.

O colégio foi inaugurado no dia 10 de junho de 1995, durante o governo de Jaime Lerner. Em síntese, é mantido pelo poder público estadual, administrado pela Secretaria de Estado da Educação (SEED), nos termos da legislação em vigor e pela Deliberação n ${ }^{\circ}$ 16/99 - Conselho Estadual da Educação $^{14}$. A finalidade é atender aos alunos do bairro Porto Belo e circunvizinhos: Jardim Nova Califórnia I e II, Vila São Sebastião e Jardim Itaipu e outros próximos. O primeiro nome era Escola Estadual do Porto Belo - Ensino do $1^{\circ}$ grau, na época. A autorização de funcionamento foi concedida pelo prazo de 2 anos, a partir do início de 1986, para ministrar, de forma gradativa, o ensino correspondente às quatro últimas séries do $1^{\mathrm{o}}$ grau. Com o aumento da demanda de alunos (ano de 1988), foi prorrogado o prazo de autorização.

Tendo em vista a impossibilidade de o colégio continuar com o nome do bairro, pois já pertencia ao loteamento Jardim Marisa, foi feita a solicitação de mudança, ocasião em que a instituição começou a adotar o nome de uma professora que trabalhou desde sua fundação. Passou assim, em 1993, a denominar-se Colégio Estadual Professora Carmelita de Souza Dias. No ano seguinte (1995), com a criação do ensino médio, teve como sede, a título de empréstimo, as instalações da Escola Municipal Monteiro Lobato, transferindo-se, no dia de 09 de maio de 1995, em definitivo, para o prédio próprio à Rua Pedro João Medeiros, no 129, Jardim Marisa, onde funciona até os dias atuais. A instituição atende do $6^{\circ}$ ao $9^{\circ}$ ano (manhã e tarde) do ensino fundamental; da $1^{\mathrm{a}}$ a $3^{\mathrm{a}}$ séries (manhã e noite) do ensino médio; e, a Educação de Jovens e Adultos (EJA) - no período noturno.

O colégio dispõe de 14 salas de aulas distribuídas em três pavimentos, uma quadra de esportes coberta, um laboratório de informática, secretaria, sala dos professores sala da direção, sala da equipe pedagógica, cozinha, refeitório, sala de recursos multifuncional para atendimento dos alunos com

\footnotetext{
${ }^{12}$ Idade apontada pela literatura da temática como a mais vulnerável.

${ }^{13}$ Ressaltando que cada um pode declarar-se da cor que lhe convier.

${ }^{14}$ Dados obtidos no Projeto Político Pedagógico da instituição (PPP), mediante a autorização do TCLE (anexo IV) da Resolução 196/96.
} 
déficit de aprendizagem, uma biblioteca com cerca de 2.000 exemplares, pátio e demais espaços. Conta com cerca de 100 funcionários - desde a direção ao porteiro - e aproximadamente 949 alunos ${ }^{15}$ pertencentes às classes média e baixa. Os que moram um pouco distante da instituição, os pais levam de carro. Para obter informações sobre o rendimento escolar e comportamento dos alunos, os pais e/ou responsáveis comparecem quando são solicitados pela direção, pela equipe pedagógica ou pelos professores. Ao final de cada bimestre, os alunos com notas acima da média (60) recebem os boletins e os que estão abaixo da média, só os responsáveis podem retirar.

Os adolescentes declarantes possuem suas características próprias, mas, de maneira geral, assemelham-se à maioria dos que circulam na sociedade atual. Em alguns, as características físicas são visíveis como, por exemplo: cabelo tingido nas pontas (vermelho, loiro, azul, etc.), seja longo ou curto; uma pequena parcela das meninas se destaca pela maquiagem (escura) muito marcada nos olhos e batons em tom vermelho, rosa pink ou coral; as vestes são calças justas, miniblusas/saias/shorts e, complementando o visual, muitas pulseiras e brincos/argolas enormes. As que usam saias no joelho pode-se deduzir que frequentam algum segmento religioso mais conservador, pois não usam maquiagem e nem acessórios chamativos (brincos e pulseiras grandes). Quanto aos do gênero masculino, a questão é o uso de camisetas de cor escura, com estampas grandes e coloridas; as calças grandes e caídas (provavelmente, uns dois números a mais que o manequim do usuário) aparecendo metade da peça íntima. Os adolescentes elaboram sua linguagem própria para dialogar, namorar, trocar experiências e vivenciarem afinidades, além de buscarem garantir a autonomia de inserção entre os grupos, mesmo sendo transitórios, principalmente, no ambiente escolar. (BAQUERO, 2008).

No que se refere à violência no bairro, um dos elementos apontados (pelos entrevistados) como colaborador da violência social no local, que influencia no ambiente escolar, é o envolvimento de muitas famílias com práticas ilícitas e a sua proximidade com o Rio Paraná, local por onde entra o contrabando, armas e drogas vindas do Paraguai. Para 58,92 \% dos adolescentes ouvidos, o Porto Belo é violento e as razões atribuídas foram: o acerto de dívidas (68,96\%), o tráfico de drogas $(62,06 \%)$ e contrabando (37,93\%). Justificam suas afirmações dizendo que há muitos crimes; que no local tem muito bandido e pessoas mal intencionadas; que morre quem está envolvido (a) com drogas e

\footnotetext{
${ }^{15}$ Dados atualizados em 02 de setembro de 2014 com a secretária do colégio.
} 
contrabando; que a região tem épocas de efeito dominó, ou seja, acontece uma morte seguida da outra (por vingança), depois acalma e, que tempos depois, recomeça. Como também, que as mortes não têm período e nem horário para acontecerem.

Os adolescentes acreditam que a região não será tranquila, pois o tráfico de drogas não acabará nunca. Por outro lado, os interlocutores que disseram não haver violência no bairro pesquisado foram de 41,08 \%. Eles explicam que não é com frequência que ocorrem os crimes; que nada aconteceu com ele (a); ou que na rua onde mora não ocorre nada. Na entrevista aberta, citaram o "Magrão" 16 que ajudava pessoas que precisavam dele, que participava de algumas atividades comunitárias e esportivas no bairro. Quando uma casa era roubada ou outro objeto qualquer, descobria quem era e mandava devolver os pertences aos donos. Quando estava vivo não aconteciam assaltos no bairro e que após a sua execução acontece, principalmente, aos turistas que visitam o Templo Budista. O que sugere a tese do bom bandido.

\section{Os adolescentes e a violência $n a$, da e contra a escola.}

O ser adolescente, perante o Estatuto da Criança e do Adolescente e legislação complementar deve gozar da proteção integral sob a Lei Federal nº 8.069 (BRASIL, 1990). É todo indivíduo com idade entre doze e dezoito anos. Somente a partir da promulgação da referida legislação, o ser adolescente ganha status de sujeito, portanto, cidadão com os direitos garantidos, conforme se cita abaixo:

A criança e o adolescente têm direito à liberdade, ao respeito e à dignidade como pessoas humanas em processo de desenvolvimento e como sujeitos de direitos civis, humanos e sociais garantidos na Constituição e nas leis. (BRASIL, 1990, p. 20).

\footnotetext{
${ }^{16}$ Acusado pelo GAECO - Grupo de Atuação Especial de Combate ao Crime Organizado - de ordenar a morte de mais de 30 pessoas no mundo do tráfico e era apontado como um dos comandantes do esquema na região do Porto Belo. Foi executado com mais de 50 tiros no dia 12/09/2013.
} 
Levisky (2000) enfatiza que os adolescentes, com suas características biopsicossociais, tendem, de maneira espontânea e natural, descarregaram seus impulsos agressivos através de expressões impulsivas sem pensar nas consequências, e que, em muitas situações, pensam depois do ato concretizado, ou seja, "são vias de expressão rápidas e buscam satisfação imediata dos desejos sem passar pelos critérios de avaliação, simbolização e linguagem” (p. 21). Para o mesmo autor, é na fase da adolescência que o indivíduo tem uma dificuldade enorme de conviver com regras, e talvez a maneira "democrática" como a sociedade se organiza com certas normas, em condições de igualdade para todos - isso vale para o essencial, mas existem as diferenças que precisam ser respeitadas. Ressalta ainda que, na sociedade contemporânea, é comum a mídia propagar violências cometidas contra e pela juventude dentro de uma sociedade cada vez mais global, "muitas vezes cruel, injusta e desigual em suas oportunidades" (2000, p. 23).

Em específico ao ambiente escolar, Alba Maria Zaluar (2010) ressalta que os comportamentos “desviantes fora do padrão social” são justificados pela razão do espaço escolar tornar-se um lugar de docilização e disciplinamento dos corpos, ou seja, é um ambiente onde não há espaço para o educando expressar suas ideias, seja através da pintura, da dança e da dramatização, entre outros. Segundo a mesma autora, criou-se, dentro do ambiente educacional, um sistema de regras e normas que precisam estar em constante vigilância. Se o espaço escolar não oferece essa oportunidade de expressão, não explora as potencialidades dos seus integrantes, os induz a canalizarem para as práticas difusas e transgressoras no espaço urbano e/ou escolar.

Neste sentido, Elis Maria Teixeira Palma Priotto (2011) afirma que a violência é um fenômeno caracterizado por várias manifestações no seu cotidiano. Para a autora, a violência são práticas usuais no ambiente "por e entre professores, alunos, diretores, funcionários, familiares, (ex) alunos, pessoas da comunidade e estranhos" (p. 96). Tais ações acontecem de diferentes maneiras, que vão desde a agressão física/verbal, às drogas - uso, oferta, venda e distribuição de álcool, maconha, tabaco e outros. São episódios que ocorrem no espaço interno (salas, corredores, pátio, etc), no portão de entrada e/ou na via pública. Em relação aos tipos de violência no ambiente escolar, Priotto (2011) pontua que:

A violência contra a escola é representada como atos de vandalismo, incêndios e destruição, roubo e furtos do patrimônio como paredes, cadeiras, carteiras, 
portas, cabos de fiação, cabos de telefone, materiais e equipamentos das instituições escolares; em relação à violência $d a$ escola, mostra-se todo tipo de práticas utilizadas pela instituição escolar que prejudicam os seus membros como: os fracassos escolares, falta a de interesse em permanecer na escola, o conteúdo alheio aos interesses dos alunos e do mercado de trabalho, os preconceitos (racismo). A indisciplina, a expulsão, a intimidação, o ameaçar abuso do poder baseado no consentimento que se estabelece e se impõe mediante o uso de símbolos de autoridade por parte dos professores, diretores e supervisores (...); a violência $n a$ escola, em alguns casos, deve ser analisada como a violência $d a$ escola: o aluno agredir o professor ou usar forças ou não contra o professor, o diretor ou funcionário. Caracteriza-se numa violência gerada através da maneira como a instituição e seus agentes tratam em virtude de regras e normas estabelecidas. (PRIOTTO, 2011, pp. 96-97).

Para um melhor entendimento da temática da violência $n a$, da e contra a escola no ambiente pesquisado, foram consultados os registros nos livros Atas que, de certa maneira, são mais utilizados como prática punitiva do que como ação de orientação. Contudo, merecem ser discutidos no sentido de demonstrar a amplitude e a complexidade dos episódios ocorridos na instituição escolar. No colégio, existem três diferentes tipos de livros de registros (cada um específico para a situação): um é para os registros mais graves quando a Patrulha Escolar é acionada pela equipe pedagógica ou pela direção; o outro é para situações diversas que acontecem em cada turno; e, o terceiro é específico por turma, no qual constam anotações individuais de cada aluno (atrasos, rendimento no aprendizado, indisciplina, entre outros). Em ambos, encontra-se a violência $n a$, da e contra a escola.

$\mathrm{Na}$ tabela 1, constam os registros mais frequentes encontrados nos documentos analisados (dos três turnos) na instituição escolar no ano de 2013 e primeiro semestre de 2014.

Tabela 01: Registros dos livros-ata do colégio.

\begin{tabular}{|l|c|}
\hline \multicolumn{1}{|c|}{ Descrição dos atos: } & Quantidade: \\
\hline Desacato ou agressão verbal do aluno para com o professor: & 31 \\
\hline Agressões físicas e verbais entre alunos (as): & 29 \\
\hline Danos ao patrimônio público causado por alunos: & 15 \\
\hline Desacato e ameaça à pedagoga ou direção: & 09 \\
\hline
\end{tabular}


Percebe-se, na tabela, que as agressões envolvendo os alunos predominam seja em relação aos professores, seja entre eles. A situação sugere que a violência social seja um dos fatores desencadeadores dos conflitos envolvendo os adolescentes, ou seja, de situações mal resolvidas fora do contexto escolar. $\mathrm{Na}$ verdade, o assunto violência no ambiente escolar deve ser abordado em várias disciplinas (português, história, sociologia, filosofia e ensino religioso, entre outras), partindo da ideia de que é necessário um processo coletivo de todos os envolvidos na educação. Dessa forma, todos se sentirão responsáveis por criarem um ambiente saudável e seguro para o desenvolvimento da aprendizagem e ainda que:

A violência está no cotidiano da escola e, nesta concepção, para trabalhar como o problema diário, tem que ter prática pedagógica, educativa como aprendizagem e reflexão por parte dos alunos, professores, direção, familiares e demais membros da comunidade escolar, todos com um mesmo objetivo de construir uma visão crítica sobre o assunto, para então propor alternativas concretas para superá-las. (PRIOTTO, 2011, p. 152).

Em relação à violência contra a escola, há o outro lado dessa violência que é o desvio de verbas públicas, abandono dos prédios públicos e péssima remuneração dos profissionais da educação, etc. Prédios pobres, sujos, degradados, onde ninguém quer estar - nem aluno, nem professor - por isso, o aluno que não tem estímulo se evade, seja desistindo, seja pulando o muro e indo embora mais cedo. Uma das precauções adotada pelo colégio foi aumentar o muro (mais 1 metro) após um ex-aluno pular e adentrar para matar outro que estava em sala de aula e também devido a um atentado contra a instituição, como represália pela apreensão de uma moto na frente do colégio que perturbava o andamento das atividades escolares. $\mathrm{O}$ que se percebe é que a estrutura física das unidades de ensino ganhou uma nova arquitetura: muros altos, grades, portões fechados e equipamentos de segurança (câmeras e alarmes).

No contexto escolar pesquisado, existem câmeras na parte administrativa, no refeitório e nos corredores das salas. Um dos problemas enfrentados pela direção do colégio é o desafio de conseguir manter a estrutura física em condições adequadas de uso, pois o vandalismo contra o patrimônio 
público (tabela 1) é considerado alto. Todo início de ano letivo são realizados reparos e, em pouco tempo (um bimestre), já se percebe carteiras e paredes riscadas, portas e fechaduras arrancadas, ventiladores e vidros quebrados, entre outros danos. Porém, essa conscientização deveria tornar-se estender-se por todo período letivo. Neste sentido, a alternativa encontrada para não arcar com as despesas, foi regimentar, e quem danificar será chamado(a) e pagará pelo dano. Segundo o diretor, para o ano letivo de 2014, foi liberada uma verba destinada para a reforma. Com a mesma foram realizados reparos nos banheiros, pintura externa e adequação (rampas) para acessibilidade dos portadores de necessidades especiais.

Entretanto, considerando toda estrutura física do colégio, de maneira geral, consta que a sensação é de desânimo e de que o esforço não vale a pena (WESTPHAL e BYDLOWSKI, 2010, p. 226). A definição é de que a escola, atualmente, representa um lugar de reprodução de miséria. Contudo, é possível reverter à situação aproximando, criando saber, conhecimento e abrindo para a comunidade, assim estabelecerá relações mais próximas. De maneira geral, a violência contra a escola são as pichações, depredações e bombas nos banheiros segundo as mesmas autoras. É preciso pensar em "violências" diversas e múltiplas que necessitam ser percebidas em todas as suas dimensões. Como também, elaborar práticas que colaborem para "soluções" duradouras e que permitam o agir coletivamente, o agir de maneira cidadã. Ainda que, geralmente, as situações de violência no interior da escola tornam-se um círculo vicioso envolvendo a vítima e o agressor. Nesse aspecto, os registros, nos livros ata, são de bomba caseira (na sala de aula e no corredor das salas), destruição de carteiras, ventiladores e de extintores.

Por outro lado, as ameaças registradas de alunos para com os professores e direção podem ser consideradas graves. Nos livros ata encontrou-se o seguinte conteúdo relacionado à violência $n a$ escola: aqui dentro você manda, lá fora somos nós; a partir de amanhã sua vida será um inferno; registro de alunos que fotografaram o carro dos professores/direção no pátio; cuidado por onde anda; xingamentos à pedagoga, entre outros. Embora exista um conjunto de variáveis relacionado à violência no ambiente escolar, as autoras Westphal e Bydlowski (2010, p. 229) lembram que professores de diferentes disciplinas mal se conhecem, parecem pertencer a distintas escolas, por lecionarem suas aulas em turnos opostos, ou seja, é como se o contexto escolar fosse um lugar de passagem. O que a título de 
hipótese não há vínculo nem com o ambiente, nem com os que fazem parte dele: professores, alunos, funcionários e comunidade.

Outro aspecto pontuado por Priotto (2011) no quesito da violência na escola é o bullying ${ }^{17}$ que se sobressai em relação à agressão física. No contexto pesquisado, existem situações de transferência do aluno para outra escola por medo e/ou porque recebeu ameaça e recusa-se a ir à escola. O que, a título de hipótese, quando não ocorre a transferência, há o abandono dos estudos. Conforme a mesma autora, "atitudes como ofender, ignorar, excluir, ferir e humilhar, sempre foram encontradas nas escolas públicas ou particulares” (p. 93). Ainda segundo a autora, o bullying é mais sério porque colabora para a "vítima" isolar-se, sentir-se insegura, e até mesmo, discriminada, o que, em alguns casos, contribui para a evasão escolar ${ }^{18}$. Neste aspecto, existe muita reclamação por parte dos professores sobre a falta de respeito, dos alunos, para com os mesmos.

Na concepção de Priotto (2011, p. 96), a violência da escola é uma reversão do que foi descrito, anteriormente, pois as práticas educativas adotadas pelo processo educativo são as que prejudicam os membros que a frequentam. Nos registros consultados, encontraram-se anotações referentes aos alunos de ambos os gêneros como: remanejado (a) de horário; fraco (a); desinteressado (a); apático (a); com baixo rendimento; não faz atividades, entre outros. As autoras Westphal e Bydlowski (2010) vão mais além dos registros mencionados: o não ensinar, currículos defasados, aulas monótonas (com quadro/giz), além da discriminação (gênero, raça, condição social, opção sexual, etc.) presente no ambiente escolar. Fatores que sugerem a ocorrência do abandono, faltas e desistências. Nesse aspecto, as autoras sugerem a implantação de um projeto pedagógico coletivo local para o desenvolvimento local envolvendo parcerias com acadêmicos, escola, comunidade e poder público.

\footnotetext{
${ }^{17}$ Bullying é originada da palavra inglesa bully que na forma de verbo indica a ação de ameaçar, intimidar. PRIOTTO (2011, p. 94).

${ }^{18}$ Os dados obtidos são de 2012 onde a taxa de evasão foi 24, 3 \% no Brasil. O relatório do BID - Banco Interamericano de Desenvolvimento - entre os jovens mais pobres, menos de um terço conclui o ensino médio no Brasil (https://www.brasil.gov.br). No Paraná, em específico, na região Oeste a evasão atinge um em cada 17 alunos. Conforme dados do IBGE (Censo 2010), em Foz do Iguaçu foi de 5, 63 \% (https:/www.oparana.com.br) A evasão do ensino médio (noturno) no colégio pesquisado, em 2013, foi de 30,58 \%. Muito acima dos demais índices apresentados.
} 


\section{Considerações Finais.}

O objetivo inicial do estudo foi analisar o fenômeno da violência entre os jovens no bairro Porto Belo, pois muitas eram as notícias reportadas pela imprensa (telejornais, jornais e programas de rádio) os envolvendo em assassinatos/homicídios, em tráfico de drogas e/ou em contrabando, já que, a região é considerada um corredor de passagem dos produtos ilícitos oriundos do Paraguai devido ao fácil acesso ao Rio Paraná, por onde é transportada a maioria dos itens que entram no país de maneira clandestina.

Contudo, na medida em que o trabalho foi sendo construídos novos elementos apresentados nas entrevistas realizadas contribuíram para que se focasse, especificamente, nos adolescentes no ambiente escolar, pois os conflitos os envolvendo estavam acontecendo com mais frequência no universo do colégio estadual do bairro. Assim, buscou-se identificar a violência escolar, que corresponde a toda violência $n a$, da e contra a escola. Nesse momento, sentiu-se a ausência de ações que possam contribuir para amenizar os conflitos entre os adolescentes no interior do contexto pesquisado.

A partir dos registros nas atas do colégio, foi possível constatar que os sujeitos pesquisados são vítimas do sistema escolar (violência $d a$ escola) ao assinarem anotações com os termos: desinteressado(a), apático(a), fraco(a) e remanejado(a) de horário, entre outros. Neste aspecto, estão sendo vitimados pela escola. Verificou-se que a relação entre a violência e o ambiente escolar é constante, pois foram constatados diferentes registros que confirmam a existência do fenômeno no colégio pesquisado: agressões físicas e verbais entre alunos, desacato e desrespeito aos professores, danos ao patrimônio público, ameaças a professores/pedagogo/direção, uso de drogas (álcool, cigarro, maconha), remanejamento do aluno de horário, punições com advertências verbais e escritas, entradas de estranhos no espaço escolar (pulando o muro), entre tantas outras.

Os adolescentes entrevistados reconhecem a existência da violência no espaço escolar e na região. Mas também, admitem que, às vezes, ultrapassam os limites no que diz respeito às reações agressivas que praticam dentro do colégio quando professores/pedagoga/direção tomam algumas 
atitudes para solucionar as manifestações que acontecem no interior da instituição. Não suficiente, sabem que determinadas brigas são decorrentes de problemas mal resolvidos fora do colégio.

No que se refere à violência na escola, é caracterizada por várias manifestações no cotidiano diário dos livros-ata e da Patrulha Escolar praticada por todos os membros da escola (alunos, professores, pedagogos, direção e funcionários). Os registros mais comuns foram o de desacato ou desrespeito para com os professores e agressões físico/verbais entre os educandos. Além de que, em algumas situações de ameaças, as vítimas preferem não representar judicialmente o fato ocorrido.

O principal ponto a ser destacado nas análises das entrevistas é o de que a violência no ambiente escolar gera insegurança, medo, estresse e, às vezes, impotência por parte dos professores e corpo administrativo. São situações que causam desânimo para a realização da função com estímulo. $\mathrm{Na}$ verdade, entende-se que a violência no espaço escolar necessita de atenção especial para que todos os inseridos no processo ensino/aprendizagem possam juntos, encontrar possibilidades de enfrentamento do fenômeno e o ambiente torne-se mais prazeroso de ser frequentado.

Outro aspecto constatado foi à ausência de projetos na instituição de ensino que contemplem práticas educativas, e não punitivas, para amenizar o fenômeno violência no espaço escolar, e também de políticas sociais (esporte, lazer e saúde), muito bem pontuadas pelos interlocutores da pesquisa de campo, direcionadas aos interesses dos adolescentes do Porto Belo, assim, ocupados com atividades prazerosas não estariam, ociosos no contraturno, envolvendo-se com más companhias e com o ilegal (usando drogas, por exemplo). Tais elementos acabam ganhando destaque nas práticas e no imaginário, pois são associados à imagem de insegurança que a fronteira supostamente possui.

Compreende-se que algumas sugestões podem ser apontadas para diminuir os conflitos entre adolescentes no ambiente escolar como: melhorias na estrutura física e na segurança de todos que frequentam o lugar; elaboração e implantação de projetos (equipe de saúde) direcionados para a valorização individual e coletiva dos membros da escola; cursos de interesse do público entrevistado; ações educativa/culturais (competições esportivas, eventos festivos, feiras culturais, etc.) que colaborem com a aproximação de familiares e comunidade, entre outros. Contudo, sabe-se que a escola sozinha não será autossuficiente para efetuar as mudanças necessárias. É preciso o empenho e compromisso de todos com o processo educacional para que o ambiente passe a ser um lugar com 
melhores condições psicossociais para aprendizagem e desenvolvimento saudável dos alunos e de todos que dele fazem parte.

\section{Referências Bibliográficas.}

ANDRADE, Luciano de, et al. Homicídios juvenis e informalidade em um município brasileiro da tríplice fronteira Brasil, Paraguai e Argentina. Revista Panam Salud, publicação em: 31 mai. 2012. Disponível em: https://www.paho.org. Acesso em: 15 mar. 2014.

BAQUERO, Rute. O Jovem na Agenda. Ijuí: Ed. Unijuí, 2008, 312p.

BRASIL. Estatuto da Criança e do Adolescente (ECA), (Lei no 8.069, de 13 de julho de 1990). Brasília, Diário Oficial da união, 1990. Edição Reformulada.

CARDIN, Eric Gustavo. As dinâmicas das fronteiras e os jovens vítimas de homicídios no município de Foz do Iguaçu/PR (2001-2010). Século XXI. Revista de Ciências Sociais, v.3, n. 2, p.155-181, jul./dez. 2013.

As múltiplas faces das fronteiras. 1. ed. Curitiba, 2013.

CATTA, Luiz Eduardo. O Cotidiano de uma fronteira: a perversidade da modernidade. EDUNIOESTE. Cascavel, 2003.

GONÇALVES, Jonas Maurício; CASSUCE, Francisco Carlos da Cunha; GALANTE, Valdir Antonio. A influência das regiões de fronteira e de variáveis socioeconômicas na criminalidade no estado do Paraná. Perspectiva econômica. v. 6, n. p.23-44, jul/dez, 2010.

KLEINSCHMITT, Sandra Cristiana; AZEVEDO, Paulo Roberto; CARDIN, Eric Gustavo. A tríplice fronteira internacional entre Brasil, Paraguai e Argentina: contexto histórico, econômico e social de um espaço conhecido pela violência e pelas práticas ilegais. Revista Perspectiva Geográfica. UNIOESTE V.8, N.9, 2013.

LEVISKY, David Léo (Org.). Adolescência e violência: consequências da realidade brasileira. São Paulo: Casa do Psicólogo, 2000.

LIMA, Perci. Foz do Iguaçu: no contexto da sua história. Foz do Iguaçu: Ed. do autor, 2010. 
LUZ, Carlos. Tráfico ameaça a juventude em Foz do Iguaçu. Publicado em: 06, Out, 2008. Disponível em: https://www.blogdacomunicacao.com.br. Acesso em: 25, Jun, 2012.

PRIOTTO, Elis M. T. Palma. Violência escolar: políticas públicas e práticas educativas no município de Foz do Iguaçu. Cascavel: EDUNIOESTE, 2011.

RIBEIRO, Maria de Fátima Bento. Memórias do concreto: vozes na construção de Itaipu. Cascavel: Edunioeste: 2002. 116 p. Dissertação de Mestrado. Universidade Estadual do Oeste do Paraná. Cascavel/PR.

SPOSITO, Marília Pontes (Coord.). Espaços públicos e tempos juvenis: um estudo de ações do poder público em cidades de regiões metropolitanas brasileiras. São Paulo: Global, 2007.

WESTPHAL, Márcia Faria; BYDLOWSKI, Cynthia Rachid (Edit.). Violência \& juventude. São Paulo: Hucitec, 2010.

WOJCIECHOWSKI, Guilherme Dreyer. Foz de Iguaçu tem o maior índice de violência infanto-juvenil do Brasil. Postado em: 22 Abr 2009. Disponível em: sopabrasiguaia.blogspot.com. Acesso em: 25 Jun 2012.

ZALUAR, Alba Maria. Do Dinheiro e dos Homens no Tráfico de Drogas. In: WESTPHAL, Márcia Faria; BYDLOWSKI, Cynthia Rachid (Edit.). Violência \& juventude. São Paulo: Hucitec, 2010. p. 162-194. 